\title{
Characterizing Broadband Seismic Noise in
}

\section{Central London}

\author{
David N. Green ${ }^{1}$, lan D. Bastow ${ }^{2}$, Ben Dashwood ${ }^{3}$, and Stuart E. J. Nippress ${ }^{1}$
}

${ }^{1}$ AWE Blacknest, Brimpton, UK

${ }^{2}$ Department of Earth Science and Engineering, Imperial College London, London, UK

${ }^{3}$ British Geological Survey, Keyworth, UK

\section{ABSTRACT}

Recordings made at five broadband seismometers, deployed in central London during the summer of 2015, reveal the wideband nature (periods, $T$, of between 0.01 and $100 \mathrm{~s}$ ) of anthropogenic noise in a busy urban environment. Temporal variations of power spectral density measurements suggest transportation sources generate the majority of the noise wavefield across the entire wideband, except at the secondary microseismic peak $(2<T<6 \mathrm{~s})$. The effect of road traffic is greatest at short periods $(T<0.4 \mathrm{~s})$ where acceleration noise powers are $\sim 20 \mathrm{~dB}$ larger than the New High Noise Model; at $T=0.1 \mathrm{~s}$ daytime root-mean-square acceleration amplitudes are 1000 times higher in central London than at an observatory station in Eskdalemuir, Scotland. Overground railways generate observable signals both at short periods $(T<0.3 \mathrm{~s})$, which are recorded in close proximity to the tracks, and at very long periods $(T>20 \mathrm{~s}$ ) which are recorded across the city. We record a unique set of signals $30 \mathrm{~m}$ above a subway (London Underground) tunnel interpreted as a short-period dynamic component, a quasi-static response to the train moving underneath the instrument, and a very long period ( $T>30 \mathrm{~s})$ response to air movement around the tunnel network. A low-velocity clay and sand overburden tens of metres thick is shown to amplify the horizontal component wavefield at $T \sim 1 \mathrm{~s}$, consistent with properties of the London subsurface derived from engineering investigations. We provide tabulated median power spectral density values for all stations, to facilitate comparison with any future urban seismic deployments.

Keywords: Noise, Urban, Subway, London 


\section{INTRODUCTION}

2 Over the past 65 years there has been an increasing trend for people to live in large cities (United

3 Nations, 2014). Since 1990 the number of people living in cities with over 10 million inhabitants

4 ('megacities') has risen from 153 million to 453 million. Such environments are vibrationally noisy,

5 given the large volumes and dense concentrations of transportation networks and machinery. Urban

6 ground vibrations are of interest to a number of communities including, among others, engineering

seismologists (e.g., Fäh et al., 1997; Panou et al., 2005), seismic network operators (e.g., Thomas

et al., 2013), personnel detection specialists (Peck, 2008), and volcanic hazard assessors (e.g., Boese

9 et al., 2015). Therefore it is of interest to characterize noise level amplitudes in urban areas and to

10 identify the dominant sources. Here we report measurements of broadband noise across a network of

11 five broadband seismometers deployed in central London, UK, during the summer of 2015 (Figure

1). We provide an analysis of urban noise in a megacity in the early 21 st century, and take care to

provide absolute noise power amplitudes such that they can be compared against measurements in other

4 metropolitan areas or any future noise surveys within London.

London, UK, is a city with a population of 10.9 million (United Nations, 2014), that has grown around the River Thames approximately $60 \mathrm{~km}$ inland from its exit into the North Sea. Reflecting its almost 2000 year history, the city has a diverse range of urban environments and transportation networks (Figure 1). The city is served by an extensive subway system (the London Underground) and several mainline surface railway terminal stations. Road traffic density is high; in 2014 over 420 million miles of motor vehicle journeys were estimated to have been undertaken on major roads in central London (Westminster \& City of London, http://www.dft.gov.uk/traffic-counts, accessed April 2016).

London is situated on a broad syncline, referred to as the London Basin, and the subsurface has been well studied due to the numerous geotechnical and hydrogeological investigations that have been undertaken to support the construction of infrastructure (e.g., Royse et al., 2012). Beneath central London, Paleozoic basement (predominantly sandstones) lies $\geq 350 \mathrm{~m}$ below the surface, with $\sim 250 \mathrm{~m}$ of Cretaceous sandstones, clays and chalks lying unconformably above (e.g., Sumbler, 1996). The chalk 
has a thickness of $\leq 200 \mathrm{~m}$ and is mostly saturated, providing a major aquifer for the city's population. Above the chalk sit Paleogene clay and sand deposits with thicknesses of many tens of metres. These have greatly influenced the subsurface engineering beneath the city, especially the construction of the London Underground which has exploited the advantageous tunnelling properties of the London clay (e.g., Ellison et al., 2004; Royse et al., 2012). The geological sequence is topped in places, in particular close to the river Thames and its tributaries, by Quaternary alluvium and river gravel deposits. In terms of seismic response, it is expected that the upper tens of metres (clays, sands, gravels) will have low wavespeeds compared to the chalk beneath (e.g., Bourbié et al., 1987).

The observations detailed in this paper highlight the absolute noise amplitudes and temporal noise variations associated with a number of sources, including road traffic and the subway. We show that the wideband noise field for periods between 0.01 and $100 \mathrm{~s}$ is controlled by anthropogenic sources, except at the microseism peak. Our observations focus on vertical component noise amplitudes, in order to minimise the effects of seismic wavefield amplification in weak sediments (e.g., Lermo and Chávez-García, 1993). As predicted by a model derived from engineering investigation data, horizontalto-vertical component spectral ratios at each station show that site effects in London are dominated by the upper tens of metres of sediments which exhibit very low $(<400 \mathrm{~m} / \mathrm{s})$ shear wavespeeds.

\section{METHODS}

Five three-component broadband seismometers were deployed within buildings in central London between mid-July and early-September 2015. The deployments varied between two and six weeks in length, depending upon access to the host facility. Instrument details and deployment dates are given in Table 1. Within each building the seismometer was deployed on a concrete floor in the lowest level of the building; three were in basements and two were at ground level. Care was taken to minimize proximity to air-conditioning units and areas of heavy footfall, and the seismometers were encased in foam to reduce thermal effects at long periods. Sampling rates were set at 200 samples per second (sps), except IMP which was set at 100 sps.

Pre-processing of all data involved removing the manufacturer supplied instrument response, to produce velocity seismograms. Where necessary for the analysis these traces were differentiated 
to provide acceleration seismograms, or integrated to provide displacement seismograms. Prior to integration a high-pass filter that suppressed periods $>200 \mathrm{~s}$ was applied in order to reduce artifacts associated with deconvolving near-zero instrument response levels.

To assess ambient seismic noise power levels across central London, Probability Density Functions (PDFs) of Power Spectral Density (PSD) estimates were constructed using the methodology of McNamara and Buland (2004). In summary, this method takes all data recorded on a seismometer component and generates PSD estimates for each half-hour data segment using an averaged windowed Fourier Transform method. The use of half-hour segments is our one variation from the method of McNamara and Buland (2004) who use one-hour segments; the shorter windows allow us to provide better time resolution. The PSD estimates are subsequently smoothed over one-octave bands at 1/8 octave intervals. These smoothed PSD estimates are used throughout this paper to identify temporal variations in noise power at particular periods.

PSD estimates for each 1/8 octave interval across all half-hour data segments were accumulated into $1 \mathrm{~dB}$ wide power bins, from which the PDF as a function of noise power for each frequency interval was calculated (e.g., Figure 2). This processing technique has the advantage of not requiring data preprocessing to identify quiet periods (as for example, in Peterson, 1993); for urban noise studies, restricting the study to only quiet periods would significantly reduce our ability to identify temporal variations in noise levels.

Half-hour smoothed PSD estimates for the three components of motion were also used to calculate horizontal-to-vertical spectral ratios (HVSRs) at each station. The horizontal spectrum is taken to be the geometric mean of the measured north and east components. Our calculations closely follow the methodology of McNamara et al. (2015), but due to the short time period of data collection (two weeks at the shortest deployment) we took the median HVSR value at each frequency from all half-hour HVSRs to represent the average station HVSR (rather than the median of daily averages). The narrow spread of HVSR values across all half-hour records in the period range of interest, as shown in the results in Figure 6, suggests this is justified.

The following conventions are used throughout the paper. For comparison with McNamara and Buland (2004) and Peterson (1993) we report noise power levels in units of decibels (dB) with respect 
to $1\left(\mathrm{~m}^{2} / \mathrm{s}^{4}\right) / \mathrm{Hz}$, i.e., acceleration power. For example, a difference of $10 \mathrm{~dB}$ is equivalent to one order of magnitude change in power, or a factor of 3.16 in root-mean-square (RMS) acceleration amplitude, while a difference of $20 \mathrm{~dB}$ is equivalent to two orders of magnitude change in power and one order of magnitude change in RMS amplitude (see, for example, Box12.1 of Aki and Richards, 2002, for a short explanation of decibel scales). All times in this paper are reported as Coordinated Universal Time (UT), however it should be noted that the UK observes daylight saving hours during summer months (British Summer Time, or BST) which is one hour ahead of UT, i.e., BST $=\mathrm{UT}+1$. A final convention is that we refer to the London Underground as a subway, as this term is more widely used in the literature. However, Londoners wouldn't recognize this description; in the city it is simply referred to as "the Tube".

\section{OBSERVATIONS ACROSS LONDON}

The calculated vertical component noise power PDFs indicate, unsurprisingly, that seismic noise levels in London are high with respect to observatory seismometer installations (Figures 2 and 3). In particular, at periods, $T$, less than $0.8 \mathrm{~s}$, the noise acceleration power levels increase rapidly to values up to $20 \mathrm{~dB}$ higher (a factor of ten increase in RMS amplitude) than those of the New High Noise Model (NHNM; Peterson, 1993).

At periods $T<0.1 \mathrm{~s}$ noise power levels are controlled by local sources. For example, at SJP the subway beneath it generates a broadband $(0.01$ to $0.1 \mathrm{~s})$ signal peaked at $T \sim 0.02 \mathrm{~s}$. The high acceleration powers at $T=0.04 \mathrm{~s}$ exhibit an almost $20 \mathrm{~dB}$ reduction during the brief 4.6 hour weekday night-time period when subway trains do not run (Figures 2 and 4a,c). Similar diurnal effects are observed at LFS, located $60 \mathrm{~m}$ from one of London's main overground railway routes. The signal is broadband $(0.015$ to $0.3 \mathrm{~s})$, with a longer peak noise period $(0.15 \mathrm{~s})$ than that observed for the subway at SJP. In contrast to rail traffic noise, at IMP the noise at $T=0.04 \mathrm{~s}$ is dominated by a source, likely to be an air conditioning unit, that turns on at 06:00 and shuts down at 23:00 UT generating a 19dB power variation (Figure 4b,d).

At slightly longer periods $(0.1<T<0.4 \mathrm{~s})$ the noise spectra exhibit the same elevated levels (above the NHNM) until a rapid reduction in noise power of approximately $30 \mathrm{~dB}$ between $T=0.4 \mathrm{~s}$ and 
$T=1.5 \mathrm{~s}$ result in the noise spectra at all stations falling below the NHNM. This suggests that at these periods anthropogenic noise sources generate less power, with natural noise sources starting to dominate. This is consistent with the cessation of diurnal variations at longer periods $(1.5<T<20 \mathrm{~s})$. These results are comparable to recordings from Bucharest, Romania, where Groos and Ritter (2009) found that both man-made and natural sources contributed significantly to noise in the range $1<T<1.7 \mathrm{~s}$, while at longer periods natural sources had larger amplitudes.

The secondary microseismic peak is observed at $2<T<6 \mathrm{~s}$ (see diffuse noise in Figure 4a,b). At all stations, apart from SJP where broadband subway noise dominates (Figures 3 and 4a,c), the amplitude of the microseism is comparable, with a median level of $\sim-123 \mathrm{~dB}$ during the deployment period. At periods greater than the microseism peak $(T>6 \mathrm{~s})$ there is, like at very short periods, larger inter-station variability. The quieter stations (IMP, ALB and LFS) exhibit noise levels which fall within the global population of observatory noise measurements (Peterson, 1993). At periods $>10$ s these three stations exhibit clear diurnal variations; at $T=50 \mathrm{~s}$ these variations are $\sim 10 \mathrm{~dB}$ at ALB and IMP and almost $20 \mathrm{~dB}$ at LFS (see Figure S3, available in the electronic supplement to this article). The two noisiest stations at $T>6 \mathrm{~s}(\mathrm{OWB}$ and $\mathrm{SJP})$ are those that are located closest to heavy transportation routes: OWB was deployed in a basement beneath street level and close to a busy road, SJP was deployed $\sim 30 \mathrm{~m}$ above a subway line. The interpretation of the long-period vibrations at SJP is the focus of section: London Underground Effects.

Occasionally it is the temporary absence of a persistent noise source that allows the vibrations generated by the source to be quantified. One such event that occurred during the deployment was the complete shutdown of the subway system between 2015-08-05 20:30 UT and 2015-08-07 04:00 UT due to industrial strike action. Of the three stations deployed on that date (OWB, SJP and IMP), two stations (SJP, OWB) exhibited clear noise power reductions in response to the shutdown. At SJP, where the station is located almost directly above the subway tunnels, clear reductions are observed at $T<0.04 \mathrm{~s}$ and $T>4 \mathrm{~s}$, but not around $T=0.4 \mathrm{~s}$ (Figure 4a,c). At the very short periods $(T=0.04 \mathrm{~s})$ the power reduction is $\sim 10 \mathrm{~dB}$, accounting for $55 \%$ of the regular daytime power increase. At OWB a $3 \mathrm{~dB}$ reduction in daytime power at $T=0.04 \mathrm{~s}$ was observed compared to the regular $5 \mathrm{~dB}$ daytime power increase, suggesting that the subway located at a distance of $\sim 100 \mathrm{~m}$ from OWB accounts for 
$60 \%$ of the noise power at these very short periods. The shutdown generated no observable effects for $T>0.1 \mathrm{~s}$ at OWB. No noise power decreases caused by the subway shutdown were observed at IMP, which is located at a distance of $\sim 600 \mathrm{~m}$ from the nearest subway line (Figure $4 \mathrm{~b}, \mathrm{~d}$ ). For conciseness, only results for SJP and IMP were included in Figure 4. Interested readers will find graphical results for all stations in the electronic supplement to this article (Figure S2).

The observation that $T=0.4 \mathrm{~s}$ noise power at SJP is not reduced by the subway shutdown suggests that at this period the noise spectrum is dominated by another source (Figure 4c). Spectral variations across the 0.4 to $1.5 \mathrm{~s}$ passband are similar across all five stations (Figure 3), suggestive of a common city-wide generation mechanism. The most likely candidate is road traffic noise. The observation that variations at $T=0.4 \mathrm{~s}$ are diurnal at both SJP and IMP (Figures $4 \mathrm{e}$ and f), with maxima at approximately the time of the morning rush-hour (07:30 UT, 08:30 BST) and similar absolute amplitude variations (between -103 and -91 dB) suggest a ubiquitous anthropogenic source. The temporal gradients in noise power levels at $T=0.4 \mathrm{~s}$ are consistent with gradual changes in traffic volume, rather than the abrupt changes in power observed for example when air-conditioning units are turned on or off (Figure $4 \mathrm{~d}$ at $T=0.04 \mathrm{~s}$ ) or when trains start or stop travelling around the subway (Figure $4 \mathrm{c}$ at $T=0.04$ and $4 \mathrm{~s}$ ). The observation that the daytime power at $T=0.4 \mathrm{~s}$ is reduced by greater than $2 \mathrm{~dB}$ at weekends compared to weekdays, with Sundays exhibiting the largest reductions, is consistent with less traffic flow in London during the weekends. Moreover, during the weekend of 2015-08-01 and 2015-08-02, a large cycling event caused the closure of many city centre streets close to OWB and SJP during daytime periods. An increased reduction in noise at these stations compared to other weekends for $0.04<T<0.6$ (Figure 4a) indicates this passband is sensitive to road traffic noise.

In order to understand the increase in noise power due to urban sources, it is instructive to compare the noise levels measured within London with those at permanent stations in the UK. We chose to compare to two stations (Figure 1 and 3 inset). The first, BKN, is located on a concrete block in a purpose built seismic vault above clay and gravel deposits of unknown thickness. BKN is in an area of elevated daytime road traffic and within $10 \mathrm{~m}$ of offices and laboratories. The second, EKB, is located in an underground purpose built seismic vault excavated to sit on unweathered Silurian sedimentary bedrock within a quiet rural location (Truscott, 1964). 
The noise power spectra for the London and rural stations only converge at the secondary microseismic peak $(2<T<10 \mathrm{~s})$, providing additional evidence that even in cities ocean-swell generated noise dominates at these periods. Significant differences between the urban (London) and rural stations are observed at short periods $(T<1 \mathrm{~s})$. The median daytime power level at EKB is between 51 and $58 \mathrm{~dB}$ lower than in London at $T=0.4 \mathrm{~s}$, increasing to between 56 and $65 \mathrm{~dB}$ at $T=0.1 \mathrm{~s}$. At these periods EKB is approximately a factor of 1000 quieter than central London in terms of RMS amplitude. At BKN the median daytime noise levels at $T=0.4 \mathrm{~s}$ are only between 7 and $14 \mathrm{~dB}$ lower than in London, reflecting both the greater volumes of daytime traffic around BKN compared to EKB and the soft rock geology beneath the station leading to higher noise and signal amplitudes (e.g., Su et al., 1992). At night the difference in noise levels at $T=0.4 \mathrm{~s}$ between London and EKB reduces slightly to $\sim 48 \mathrm{~dB}$ due to reduced traffic noise in London, while the difference between London and BKN increases to $20 \mathrm{~dB}$ due to a larger reduction in traffic noise in the rural area around BKN. At periods $>10 \mathrm{~s}$ the rural and urban noise power levels again diverge, leading to order of magnitude differences in RMS amplitudes.

For the five central London stations, tabulated values for the 5th percentile, median, and 95th percentile noise PDFs, as a function of period (e.g., Figure 2), are provided as Table S1 (and graphically in Figure S1) available in the electonic supplement to this article, to facilitate comparisons with future urban seismic deployments.

\section{LONDON UNDERGROUND EFFECTS}

The evidence from the day of strike action suggests the influence of the London Underground (subway) on the seismic noise field does not extend more than a couple of hundred metres from the tunnel network in central London. However, recordings at station SJP indicate that train generated broadband vibrations dominate close to the subway tunnels (Figures 4 and 5). SJP was located almost directly above the two Jubilee Line subway tunnels within a room that, through a series of passageways and shafts, was connected to the tunnel network. The exact position of the seismometer relative to the subway tunnels isn't known, but in the vicinity of SJP the Eastbound/Westbound tunnels are located approximately $25 \mathrm{~m} / 35 \mathrm{~m}$ below the ground surface respectively (Willis, 1997). 
The velocity seismogram of a subway train passing beneath SJP exhibits an approximately $13 \mathrm{~s}$ long envelope, dominated by power at between $T=0.012$ and $0.05 \mathrm{~s}$ (Figure $5 \mathrm{a}$ ). Vertical peak particle velocity (PPV) measurements for the first trains each day (always Eastbound) have a mean value of $4.2 \times 10^{-5} \mathrm{~m} / \mathrm{s}$ with a standard deviation of $0.7 \times 10^{-5} \mathrm{~m} / \mathrm{s}$. PPV values generated by known Westbound trains are approximately $60 \%$ of the amplitude of those generated by Eastbound trains (the direction of travel for a subset of trains was confirmed by one author, DNG, who spent 40 minutes trainspotting on the Westbound platform of Westminster station). These values are comparable to previous vibration measurements taken above $28 \mathrm{~m}$ deep Bakerloo line tunnels; Degrande et al. (2006) found surface vertical PPV values of $\sim 1 \times 10^{-4} \mathrm{~m} / \mathrm{s}$ directly above the tunnels, dropping to $\sim 5 \times 10^{-5} \mathrm{~m} / \mathrm{s}$ at a horizontal distance of 10 to $20 \mathrm{~m}$.

Taking advantage of the broadband seismometer response, we are able to identify long-period subway generated phenomena in our data. When integrated to displacement, the vertical seismogram reveals a smooth downward then upward motion lasting approximately $9 \mathrm{~s}$ (Figure 5a). For the first Eastbound train each day the vertical downward displacement has a mean value of $5.9 \times 10^{-6} \mathrm{~m}$ and a standard deviation of $0.4 \times 10^{-6} \mathrm{~m}$. Values for Westbound trains are remarkably similar. We hypothesize that this is the quasi-static response of the seismometer to the passage of the train beneath it (see Yang and Hung, 2008, for modelling of such a phenomena). The weight of the train displaces the tunnel downwards resulting in the downward motion of the seismometer above it; the tunnel rebounds once the train has passed. Horizontal motions (not shown here) also exhibit a smooth displacement pulse, with motion directed approximately to the North-East of the station before rebounding. Although the horizontal amplitudes are over an order of magnitude larger than the vertical component $\left(>1 \times 10^{-4} \mathrm{~m}\right)$ the signal-to-noise ratio is poor due to significant long-period noise on the horizontal components.

The quasi-static displacements are superimposed on larger-amplitude, background oscillations with dominant periods of $\sim 100$ s (Figure $5 \mathrm{~b}$ ). As these oscillations do not occur on Sundays (when the train services start later) or the day of the strike, we conclude they are associated with the movement of trains in the subway network. The initial phases of this oscillation are highly correlated across different days (i.e., at 04:30), although at later times this correlation degrades. Considering the first train of the day in detail (Figure 5c) reveals that the quasi-static response occurs at the same phase point of the 
long-period oscillation each day (i.e., on the upward displacement, before the maximum), providing further evidence that this oscillation is linked to the start-up of the trains in the Eastbound tunnel. We hypothesize that this signal is the response of the seismometer to air-motion around the tunnel system, generated by moving trains displacing the air (the piston effect). For example, Lin et al. (2008) show results for an experimental study in the Taipai, Taiwan, subway system with air velocity variations having dominant periods of between $\sim 60$ and 200 s as trains moved through the network.

In our investigation the room in which SJP was installed was connected via a series of passageways to the tunnel network. Therefore, we suggest the long-period response is caused by air pressure changes around the seismometer rather than the piston effect displacing the walls of the tunnel. The piston effect mechanism is consistent with the inter-day correlation degradation as time progresses from 04:30 to 05:30 (Figure 5b). Initially the piston effect is generated by the first train through the network producing similar waveforms (the response of the tunnel and seismometer system to a single train passing). Small time-shifts (Figure 5c) reflect the slightly different times that train operations start each day (up to 90 s variability over the 15 days of recording). At later times the air piston signal is a superposition of signals generated by a number of West and Eastbound trains. Because of small changes in train transit times beneath SJP, the interference of the signals generates different seismic waveforms each day.

\section{SEISMIC EVIDENCE FOR A LOW-VELOCITY OVERBURDEN}

The observed seismic noise amplitudes are controlled by both the noise source amplitudes and the subsurface seismic propagation conditions. As described in the introduction, the upper tens of metres of the geological profile beneath central London are predominantly clays and sands.

We utilize the horizontal-to-vertical spectral ratio (HVSR) method (see Methodology section) in order to probe the subsurface structure using the noise data. Clear HVSR peaks are identified at approximately $1 \mathrm{~Hz}$ (Figure $6 \mathrm{~b}$ and $\mathrm{c}$ ) which we interpret as the primary sediment layer response frequency (e.g., Nakamura, 1989). These peaks are well defined across all time periods (Figure 6b), and are not significantly broadened at times of higher noise amplitudes.

To guide our investigations, and for the purposes of seismic propagation modelling (not shown), the British Geological Survey constructed a highly simplified 3D four-layer model for the central London 
subsurface. The layers are identified as: (1) overburden, which incorporates all superficial and bedrock lithologies above the chalk, (2) unsaturated chalk, (3) saturated chalk, where the distinction between unsaturated and saturated is derived from observed groundwater levels across the Greater London area (Environment Agency, 2015) and (4) bedrock, consisting of all lithologies beneath the chalk to a nominal depth of 5000m below Ordnance Datum. Using geotechnical parameters measured during extensive ground investigations throughout London, depth-dependent seismic velocities $\left(V_{p}, V_{s}\right)$ and material densities $(\rho)$ were attributed to each layer (e.g., Figure 6a and Table 2). The model identifies a sharp seismic transition between Paleogene sediments in the overburden (subscript $o$ ), and the chalk (c); shear wave impedance contrasts $\left(\rho_{o} V_{s, o} / \rho_{c} V_{s, c}\right)$ for the profiles beneath the five seismometers are estimated as $0.27 \pm 0.01$.

The generation mechanism for HVSR peaks is not fully understood, with the relative contributions of vertically incident $S H$ waves and the ellipticity of the fundamental Rayleigh wave still keenly debated (e.g., Nakamura, 2000; Fäh et al., 2001). However, numerous studies (e.g., Ibs-von Seht and Wohlenberg, 1999) show that HVSR spectral peaks are consistent with the shear wave resonance frequency, $f_{\text {est }}(\mathrm{Hz})$, of a single sediment layer estimated as,

$$
f_{\text {est }}=\frac{V_{s, o}}{4 H_{o}},
$$

where $V_{s, o}$ is the mean shear-wave speed in the overburden $(\mathrm{m} / \mathrm{s})$ and $H_{o}$ is the overburden thickness (m) taken in our study to be the depth to the chalk. Although probing the physical mechanism for the HVSR technique is beyond the scope of this paper, we note the similarity of Equation 1 to the theoretical relationship between vertical $P$ wave resonance in low-velocity sediments and the Rayleigh wave spectral amplitude peak (Hudson and Douglas, 1975), suggesting an analogous relationship may exist for the SH wavefield.

Despite the simplifying assumption of a single-velocity overburden layer, the $f_{\text {est }}$ values are consistent with the measured peak frequencies ( $f_{\text {measured }}$ ) of $\sim 1 \mathrm{~Hz}$ (Table 2 ) although $f_{\text {est }}$ consistently underestimates $f_{\text {measured }}$ by between 7 and $25 \%$. We note that some of the inter-station variability is captured by the model. For example, the larger sediment thickness at IMP leads to a lower $f_{\text {est }}$ 
prediction compared to the other stations, which is clearly seen in the data (Figure 6c). As a check that the methodology is not generating spurious $1 \mathrm{~Hz}$ peaks, the HSVR at the hard rock seismic vault EKB was also calculated. As anticipated, the results show no sediment layer resonance (Figure 6c).

The good correspondence between observed and predicted HVSR peaks indicate that the very low median shear wavespeeds in the overburden $(\sim 250 \mathrm{~m} / \mathrm{s})$, estimated from engineering investigations, correctly reflect the subsurface wavespeed structure. Previous work suggests that HVSR peaks are generated by a large amplification of the horizontal wavefield by the low-velocity overburden, compared to the low or negligable amplification of the vertical wavefield (e.g., Lermo and Chávez-García, 1993). In the case of central London the method is highly sensitive to the large impedance contrast between the low velocity sands and clays and the higher velocity chalk. The implication is that comparison of vertical noise power spectra between urban areas is likely to provide information regarding the sources of noise, whereas comparison of horizontal spectra will contain both source and site information. In the case of London, the low-velocity overburden appears to amplify horizontal noise power at $\sim 1 \mathrm{~s}$ (predominantly road traffic noise) by a factor of 4 (approximately $6 \mathrm{~dB}$ ) compared to the vertical noise power.

\section{DISCUSSION}

The observation that central London is subject to high amplitude seismic noise when compared to observatory grade stations is not surprising, yet comparison with other urban areas is difficult. While a number of other cities have been subject to seismic noise investigations (e.g., Fäh et al., 1997; Groos and Ritter, 2009; Riahi and Gerstoft, 2015), there are few reports of standardized power spectral density estimates. An exception to this is a study of noise at a single site in Auckland, New Zealand (Boese et al., 2015), a coastal city with a population of approximately 1.4 million (2013 figures, http://www.stats.govt.nz, accessed April 2016). Boese et al. (2015) show that median surface daytime noise values in the 0.1 to $0.4 \mathrm{~s}$ passband fall between -110 and $-120 \mathrm{~dB}$, approximately $20 \mathrm{~dB}$ (a factor of 10 in RMS amplitude) less than the values reported across London and more comparable with those seen at the semi-rural UK station BKN (Figure 3). However, Boese et al. (2015) show that at the noisiest times there is a distinct shift towards noise values of between -90 and $-110 \mathrm{~dB}$ in the 0.1 to $0.2 \mathrm{~s}$ 
passband, which are within the range of noise values observed in central London. Because these high noise values are prevalent at times of high road use (1:30 to 3:30pm local time), Boese et al. (2015) suggest that heavy traffic is the source. Other differences between the urban noise spectra can also be observed; reflecting Auckland's position close to shallow coastal waters, the microseismal noise is approximately $10 \mathrm{~dB}$ greater than observed in London.

The sources of noise across the central London network are closely linked to transportation networks: road, rail and subway. The spectral signatures of each transportation type agree well with previous studies (Table 3).

Road traffic noise appears to dominate recordings between 0.1 and $\sim 1.5 \mathrm{~s}$ in central London, with remarkably similar spectral content across all stations (Figure 3). This is in contrast to a study of traffic generated noise in Long Beach, California, which showed an increase in longer period $(0.25 \mathrm{~s})$ noise at stations closer to an interstate highway compared to stations close to local roads (Chang et al., 2016). A likely reason for this difference is that in contrast to the fast moving heavy goods vehicles on the US interstate, throughout central London traffic density is high, and traffic speeds are low, leading to a more homogeneous distribution of traffic sources. Indeed, at $\mathrm{T}=0.4 \mathrm{~s}$ the noise levels at OWB and SJP are very similar (Figure 3c and d) even during periods when the subway is running almost directly beneath SJP, indicating the dominance of road traffic noise at these periods.

The observations of three types of signal (dynamic, quasi-static and air-piston) associated with the passage of subway trains beneath station SJP highlights the complicated nature of the wavefield close to moving sources. The use of broadband seismometers is key to revealing the long-period wavefield associated with mass movement (the quasi-static response) and air motion (the long-period oscillations). We do not attempt to model the subway generated quasi-static displacement amplitudes. Although such modelling has been undertaken previously (e.g., Yang and Hung, 2008), at SJP any model will be poorly constrained as a result of uncertainties including the position of the tunnels with respect to the seismometer, the properties of the geological overburden, and the distribution of the moving load.

Non-transportation sources will also contribute to the seismic noise spectra. Groos and Ritter (2009) observed increased short-period ( 0.02 to $0.04 \mathrm{~s}$ ) noise close to areas of heavy industry in Bucharest, Romania, suggesting that machinery noise can dominate at very short periods. Due to the lack of heavy 
industry in central London we do not observe such features, although it is suspected that air-conditioning units generated the short-period signal $(T=0.04 \mathrm{~s})$ at IMP (Figure $4 \mathrm{~d})$.

Strong wind has also been shown to generate seismic noise in urban environments (e.g., Groos and Ritter, 2009; Boese et al., 2015). In Bucharest, seismic power increases could be correlated with periods of strong wind in a period range of 0.8 to $1.7 \mathrm{~s}$, a transitional zone between man-made signals at shorter periods and microseismal noise at longer periods (Groos and Ritter, 2009). In London strong diurnal noise associated with transportation sources is observable up to periods of $\mathrm{T}=1.5 \mathrm{~s}$, and the influence of the microseism is apparent at $\mathrm{T}>2 \mathrm{~s}$ (Figures 3 and 4). This leads to a narrowband transition zone between the two that, unlike in Bucharest, does not exhibit a significant reduction in noise power. Therefore we suggest any significant wind generated noise signature in the London dataset is masked by stronger sources (see Figure S4, available in the electronic supplement, for a comparison of noise timeseries with wind speed data collected $12 \mathrm{~km}$ east of Westminster at London City airport).

The increased, and diurnally varying, noise amplitudes for $T>20 \mathrm{~s}$ at stations ALB, LFS, and IMP are unexplained. Groos and Ritter (2009) suggested that such long-period motions could be caused by tilting of high-rise buildings under wind load (e.g., Breuer et al., 2008), however this is unlikely to generate the strong observed diurnal effects. In contrast, Sheen et al. (2009), show convincing evidence that diurnally varying noise in the 20 to 100 s passband recorded in both South Korea and the US can be attributed to vibrations generated by nearby trains (both overground and subway). This is consistent with the diurnal noise variations at $T>20$ s for stations ALB, LFS, and IMP, and the observation that the diurnal power variations are $10 \mathrm{~dB}$ greater at LFS which is situated $\sim 60 \mathrm{~m}$ from a major set of overground trainlines. Moreover, no reduction in power at these periods was observed at IMP during the subway strike, suggesting these variations are predominantly due to the overground railway in London.

Given the sparse nature of the deployed network, the amplitude decay of seismic waves with increasing distance from the transportation networks is poorly constrained. During the subway shutdown, stations within $100 \mathrm{~m}$ of the tunnels experienced $\mathrm{a} \sim 60 \%$ reduction in daytime noise at $\mathrm{T}=0.04 \mathrm{~s}$ while at $600 \mathrm{~m}$ from a tunnel the shutdown had no effect at the same period. Future studies focusing on measureable vibration decay away from subways such as the London Underground may benefit from 
focusing upon ranges between 100 and $500 \mathrm{~m}$ from the tunnels.

In addition to the high density of potential seismic noise sources in central London, the elevated noise amplitudes could also be a result of site effects. HVSR results confirm that the upper tens of metres beneath the stations is composed of low average $\left(V_{s} \sim 250 \mathrm{~m} / \mathrm{s}\right)$ wavespeed material (Figure 6). Although the sedimentary overburden will effect the propagation of the noise wavefield, a quantitative prediction of amplification based on the HVSR results isn't appropriate. Throughout this paper we have focused, for the sake of brevity, on vertical component power spectra which are not expected to be significantly influenced by near-surface sedimentary structure (e.g., Lermo and Chávez-García, 1993; Field and Jacob, 1995). In addition, soft sediments are expected to exhibit high seismic attenuation further complicating the prediction of noise wavefield amplification. At present the seismic attenuation structure is poorly constrained for the materials underlying London. Despite considerable differences in subsurface geology, the maximum vertical noise amplitudes observed in Auckland, New Zealand (Boese et al., 2015), and London are very similar. This suggests that the high noise amplitudes are predominantly a source effect.

\section{CONCLUSIONS}

Using recordings from five broadband seismometers in central London, we have shown that the broadband urban noise spectrum $(T=0.01$ to $100 \mathrm{~s})$ is primarily generated by transportation sources.

Road traffic noise is ubiquitous across central London between $T=0.1$ and $1.5 \mathrm{~s}$, and generates daytime RMS acceleration amplitudes at $T=0.1 \mathrm{~s}$ that are $\sim 1000$ higher than those measured at a quiet hardrock observatory at Eskdalemuir, Scotland. Diurnal variations in noise at $T=0.4 \mathrm{~s}$ follow the temporal pattern expected for road traffic, with nighttime values $12 \mathrm{~dB}$ less than those in the morning rush-hour (equivalent to an RMS acceleration amplitude reduction of a factor of four at night). Overground rail transportation exhibit clear short period signals, peaked at $\sim 0.15 \mathrm{~s}$, in the vicinity of the railway network. Railways also contribute to the very long period ( $>20$ s) noise wavefield. As expected for these longer wavelength phenomena they are observed throughout central London.

The dynamic response to the movement of trains within the subway (the London Underground) was recorded across a wide passband $(0.012<T<0.05 \mathrm{~s})$ at stations within $100 \mathrm{~m}$ of the tunnels. At a 
distance of $600 \mathrm{~m}$ no subway generated signals were observed. Observations made during an industrial strike allow us to estimate that within $100 \mathrm{~m}$ of a subway tunnel, the trains generate approximately $60 \%$ of the noise power at very short periods $(T=0.04 \mathrm{~s})$. At a station located $\sim 30 \mathrm{~m}$ above a subway tunnel, quasi-static effects associated with each train passing beneath the station were observed; the seismometer was deflected downwards by $6 \times 10^{-6} \mathrm{~m}$ before rebounding. In addition, due to the deployment of the seismometer within a room connected via shafts and passageways to the subway tunnels, we recorded the response to long period $(>30$ s) air motions throughout the tunnel network generated by the air piston effect.

A low-velocity $\left(V_{s}<400 \mathrm{~m} / \mathrm{s}\right)$ overburden beneath London, tens of metres thick, and comprising clays and sands, amplifies the horizontal noise wavefield at periods of approximately $1 \mathrm{~s}$. To minimise such sites effects in future comparisons of urban noise levels it will be important to compare vertical noise power values.

The observations show that broadband measurements are key to analyzing the full spectrum of anthropogenic vibration noise. We have provided tabulated power spectral density values, available in the electronic supplement to this article, for periods between 0.014 and $70 \mathrm{~s}$, which will facilitate comparison with future urban seismic deployments. As urban areas grow, and transportation networks evolve, it will be of interest to observe how urban seismic noise changes.

\section{DATA AND RESOURCES}

Seismic data used in this study were collected using a temporary network of AWE and Imperial College sensors, and cannot be released to the public. Analysis was facilitated by using the Obspy Python Package (Beyreuther et al., 2010). Plots were made using the matplotlib package (http://matplotlib.org), with mapping data from OpenStreetMap, which is available under the Open Database License (specifically, the ESRI shapefile download function at http://www.bbbike.org/)

\section{ACKNOWLEDGMENTS}

The assistance of Kevin Kennett and other AWE colleagues in the deployment of instrumentation is greatly appreciated. Our contacts at the various deployment locations are thanked for providing access. 
Ian Bastow acknowledges support from Leverhulme Trust grant RPG-2013-332. Ben Dashwood has

published with the permission of the Executive Director of the British Geological Survey (NERC).

\section{REFERENCES}

Aki, K. and Richards, P. G. (2002). Quantitative Seismology. University Science Books, Sausalito, California, 2nd edition. pp. 700.

Behm, M., Leahy, G. M., and Snieder, R. (2014). Retrieval of local surface wave velocities from traffic noise - an example from the La Barge basin (Wyoming). Geophys. Prosp., 62(2):223-243.

Beyreuther, M., Barsch, R., Krischer, L., Megies, T., Behr, Y., and Wassermann, J. (2010). ObsPy: A Python toolbox for seismology. Seism. Res. Lett., 81(3):530-533.

Boese, C., Wotherspoon, L., Alvarez, M., and Malin, P. (2015). Analysis of anthropogenic and natural noise from multilevel borehole seismometers in an urban environment, Auckland, New Zealand. Bull. Seism. Soc. Am., 105(1):285-299.

Bourbié, T., Coussy, O., and Zinszner, B. (1987). Acoustics of Porous Media. Gulf Publishing Company, Houston, TX.

Breuer, P., Chmielewski, T., Górski, P., Konopka, E., and Tarczyński, L. (2008). The Stuttgart TV Tower - displacement of the top caused by the effects of sun and wind. Eng. Struct., 30(10):2771-2781.

Chang, J. P., de Ridder, S., and Biondi, B. L. (2016). High-frequency Rayleigh-wave tomography using traffic noise from Long Beach, California. Geophysics, 81(2):B1-B11.

Chen, Q.-F., Li, L., Li, G., Chen, L., Peng, W.-T., Tang, Y., Chen, Y., and Wang, F.-Y. (2004). Seismic features of vibration induced by train. Acta Seismologica Sinica, 17(6):715-724.

Degrande, G., Schevenels, M., Chatterjee, P., Van de Velde, W., Hölscher, P., Hopman, V., Wang, A., and Dadkah, N. (2006). Vibrations due to a test train at variable speeds in a deep bored tunnel embedded in London clay. J. Sound Vibration, 293(3):626-644.

Ellison, R. A., Woods, M. A., Allen, D. J., Forster, A., Pharaoh, T. C., and King, C. (2004). Geology of London: special memoir for 1: 50000 geological sheets 256 (north London), 257 (Romford), 270 (south London), and 271 (Dartford) (England and Wales). British Geological Survey.

Environment Agency (2015). Management of the London Basin Chalk Aquifer. Status Report, 
https://www.gov.uk/government/publications/london-basin-chalk-aquifer-annual-status-report, accessed May 2016.

Fäh, D., Kind, F., and Giardini, D. (2001). A theoretical investigation of average H/V ratios. Geophys. J. Int., 145(2):535-549.

Fäh, D., Rüttener, E., Noack, T., and Kruspan, P. (1997). Microzonation of the city of Basel. J. Seismol., $1(1): 87-102$.

Field, E. H. and Jacob, K. H. (1995). A comparison and test of various site-response estimation techniques, including three that are not reference-site dependent. Bull. Seism. Soc. Am., 85(4):11271143.

Groos, J. C. and Ritter, J. R. (2009). Time domain classification and quantification of seismic noise in an urban environment. Geophys. J. Int., 179(2):1213-31.

Hudson, J. A. and Douglas, A. (1975). Rayleigh wave spectra and group velocity minima, and the resonance of P waves in layered structures. Geophys. J. Int., 42(1):175-188.

Ibs-von Seht, M. and Wohlenberg, J. (1999). Microtremor measurements used to map thickness of soft sediments. Bull. Seism. Soc. Am., 89(1):250-259.

Lermo, J. and Chávez-García, F. J. (1993). Site effect evaluation using spectral ratios with only one station. Bull. Seism. Soc. Am., 83(5):1574-1594.

Lin, C.-J., Chuah, Y. K., and Liu, C.-W. (2008). A study on underground tunnel ventilation for piston effects influenced by draught relief shaft in subway system. Appl. Therm. Eng., 28(5):372-379.

McNamara, D. E. and Buland, R. P. (2004). Ambient Noise Levels in the Continental United States. Bull. Seism. Soc. Am., 94(4):1517-1527.

McNamara, D. E., Stephenson, W. J., Odum, J. K., Williams, R. A., and Gee, L. (2015). Site response in the eastern United States: A comparison of Vs30 measurements with estimates from horizontal: vertical spectral ratios. Geological Society of America Special Papers, 509:67-79.

Nakamura, Y. (1989). A method for dynamic characteristics estimation of subsurface using microtremor on the ground surface. Railway Technical Research Institute, Quarterly Reports, 30(1).

Nakamura, Y. (2000). Clear identification of fundamental idea of Nakamura's technique and its applications. In Proceedings of the 12th World Conference on Earthquake Engineering. Auckland, 
New Zealand.

Panou, A., Theodulidis, N., Hatzidimitriou, P., Stylianidis, K., and Papazachos, C. (2005). Ambient noise horizontal-to-vertical spectral ratio in site effects estimation and correlation with seismic damage distribution in urban environment: the case of the city of Thessaloniki (Northern Greece). Soil. Dyn. Earthq. Eng., 25(4):261-274.

Peck, L. (2008). Overview of Seismic Noise and its Relevance to Personnel Detection. Technical Report ERDC/CRREL TR-08-5, Cold Regions Research and Engineering Laboratory.

Peterson, J. (1993). Observations and Modeling of Seismic Background Noise. Technical Report Open-File Report 93-322, U.S. Department of Interior, Geological Survey.

Riahi, N. and Gerstoft, P. (2015). The seismic traffic footprint: Tracking trains, aircraft, and cars seismically. Geophys. Res. Lett., 42(8):2674-2681.

Royse, K. R., de Freitas, M., Burgess, W. G., Cosgrove, J., Ghail, R. C., Gibbard, P., King, C., Lawrence, U., Mortimore, R. N., Owen, H., and Skipper, J. (2012). Geology of London, UK. Proc. of the Geologists' Association, 123:22-45.

Sheen, D.-H., Shin, J. S., Kang, T.-S., and Baag, C.-E. (2009). Low frequency cultural noise. Geophys. Res. Lett., 36(17).

Su, F., Aki, K., Teng, T., Zeng, Y., Koyanagi, S., and Mayeda, K. (1992). The relation between site amplification factor and surficial geology in central California. Bull. Seism. Soc. Am., 82(2):580-602.

Sumbler, M. G. (1996). London and the Thames Valley, volume 13. HMSO for the British Geological Survey.

Thomas, G., Koper, K. D., Burlacu, R., and Drobeck, D. (2013). A model of ambient seismic noise recorded by the Utah regional network of strong-motion seismometers. Seism. Res. Lett., 84(5):759-771.

Truscott, J. R. (1964). The Eskdalemuir Seismological Station. Geophys. J. R. Astr. Soc., 9(1):59-68. United Nations (2014). World Urbanization Prospects: The 2014 Revision, Highlights (ST/ESA/SER.A/352). Department of Economic and Social Affairs, Population Divison, United Nations Publications. ISBN 978-92-1-151517-6.

Willis, J. (1997). Extending the Jubilee Line: The Planning Story. London Transport, London, UK. 
492 Yang, Y. and Hung, H. (2008). Soil Vibrations Caused by Underground Moving Trains. J. Geotech. 493 Geoenviron. Eng., 134(11):1633-1644. 
Table 1. Details of the deployed Güralp broadband seismometers, the median acceleration noise levels at 02:00 and 08:00 (approximately the diurnal minimum and maximum, Figure $4 \mathrm{e}$ and f) at three periods, and the proximity to major noise sources.

\begin{tabular}{|c|c|c|c|c|c|c|c|c|c|c|}
\hline \multirow[t]{3}{*}{ Station } & \multirow[t]{3}{*}{$\begin{array}{l}\text { Location } \\
\text { (Lat/Lon) }\end{array}$} & \multirow[t]{3}{*}{$\begin{array}{l}\text { Deployment } \\
\text { Dates (2015) }\end{array}$} & \multirow{3}{*}{$\begin{array}{l}\text { Güralp } \\
\text { Model } \\
\text { (Corner } \\
\text { Period) }\end{array}$} & \multicolumn{6}{|c|}{$\begin{array}{l}\text { Median Acceleration Noise Levels } \\
\left(\mathrm{dB} \text { wrt } 1\left(\mathrm{~m}^{2} / \mathrm{s}^{4}\right) / \mathrm{Hz}\right)\end{array}$} & \multirow[t]{3}{*}{$\begin{array}{l}\text { Comment on } \\
\text { Noise Sources }\end{array}$} \\
\hline & & & & \multicolumn{3}{|c|}{ 02:00 GMT } & \multicolumn{3}{|c|}{ 08:00 GMT } & \\
\hline & & & & $0.1 \mathrm{~s}$ & $0.4 \mathrm{~s}$ & $1.0 \mathrm{~s}$ & $0.1 \mathrm{~s}$ & $0.4 \mathrm{~s}$ & $1.0 \mathrm{~s}$ & \\
\hline \multicolumn{11}{|c|}{ London Stations } \\
\hline ALB & $\begin{array}{l}51.52650 \mathrm{~N} \\
0.12459 \mathrm{~W}\end{array}$ & $\begin{array}{l}\text { 12-Aug to } \\
27 \text {-Aug }\end{array}$ & $\begin{array}{l}\text { 3ESPC } \\
(60 s)\end{array}$ & -88.2 & -104.9 & -130.9 & -81.1 & -95.2 & -122.8 & $\begin{array}{l}\text { No rail or subway } \\
\text { within } 200 \mathrm{~m}\end{array}$ \\
\hline IMP & $\begin{array}{l}51.49950 \mathrm{~N} \\
0.17589 \mathrm{~W}\end{array}$ & $\begin{array}{l}\text { 4-Aug to } \\
\text { 9-Sep }\end{array}$ & $\begin{array}{l}3 \mathrm{ESPC} \\
(60 \mathrm{~s})\end{array}$ & -98.5 & -103.0 & -127.1 & -89.9 & -91.5 & -118.3 & $\begin{array}{l}\text { No rail or subway } \\
\text { within } 600 \mathrm{~m}\end{array}$ \\
\hline LFS & $\begin{array}{l}51.49258 \mathrm{~N} \\
0.11992 \mathrm{~W}\end{array}$ & $\begin{array}{l}\text { 13-Aug to } \\
\text { 26-Aug }\end{array}$ & $\begin{array}{l}3 \mathrm{ESPC} \\
(60 \mathrm{~s})\end{array}$ & -94.0 & -107.9 & -130.7 & -82.5 & -96.7 & -121.0 & $\begin{array}{l}60 \mathrm{~m} \text { from overground } \\
\text { train line }\end{array}$ \\
\hline OWB & $\begin{array}{l}51.50606 \mathrm{~N} \\
0.12459 \mathrm{~W}\end{array}$ & $\begin{array}{l}\text { 28-Jul to } \\
\text { 27-Aug }\end{array}$ & $\begin{array}{l}40 \mathrm{~T} \\
(30 \mathrm{~s})\end{array}$ & -91.1 & -96.4 & -126.4 & -89.6 & -89.8 & -119.2 & $\begin{array}{l}\text { Heavy road traffic; } \\
\text { subway at } 100 \mathrm{~m}\end{array}$ \\
\hline SJP & $\begin{array}{l}51.50150 \mathrm{~N} \\
0.14388 \mathrm{~W}\end{array}$ & $\begin{array}{l}\text { 28-Jul to } \\
12 \text {-Aug }\end{array}$ & $\begin{array}{l}\text { 3ESPC } \\
(60 s)\end{array}$ & -92.8 & -102.2 & -128.9 & -83.9 & -91.2 & -119.1 & $\begin{array}{l}\text { Directly above subway } \\
\text { line }\end{array}$ \\
\hline \multicolumn{11}{|c|}{ Other UK Stations } \\
\hline$\overline{B K N}$ & $\begin{array}{l}51.36420 \mathrm{~N} \\
1.18690 \mathrm{~W}\end{array}$ & Permanent & $\begin{array}{l}\text { 3ESPC } \\
(60 s)\end{array}$ & -115.4 & -123.2 & -132.6 & -94.6 & -104.1 & -132.6 & $\begin{array}{l}\text { Semi-rural location, } \\
\text { local daytime traffic }\end{array}$ \\
\hline EKB & $\begin{array}{l}55.33386 \mathrm{~N} \\
3.19228 \mathrm{~W}\end{array}$ & Permanent & $\begin{array}{l}3 \mathrm{~T} \\
(120 \mathrm{~s})\end{array}$ & -152.0 & -151.0 & -139.0 & -145.7 & -148.2 & -139.2 & $\begin{array}{l}\text { Quiet rural location } \\
\text { local daytime traffic }\end{array}$ \\
\hline
\end{tabular}


Table 2. Properties of the overburden in the simplified four-layer geological model of London used to calculate the HVSR resonance frequency $\left(f_{\text {est }}\right)$. These are compared to measured HVSR resonance frequencies ( $f_{\text {measured }}$, see Figure 5$)$. The full-width at half maximum (fwhm) are provided to give a measure of the spectral sharpness of the peaks.

\begin{tabular}{|l|c|c|c|c|c|}
\hline Station & $\begin{array}{l}\text { Depth to } \\
\text { overburden } \\
\text { base }(\mathrm{m})\end{array}$ & $\begin{array}{l}V_{s} \\
\text { surface } \\
(\mathrm{m} / \mathrm{s})\end{array}$ & $\begin{array}{l}V_{s} \\
\text { overburden } \\
\text { base }(\mathrm{m} / \mathrm{s})\end{array}$ & $\begin{array}{l}f_{\text {est }} \\
(\mathrm{Hz})\end{array}$ & $\begin{array}{l}f_{\text {measured }},[\mathrm{fwhm}] \\
(\mathrm{Hz})\end{array}$ \\
\hline \hline ALB & 52 & 101 & 365 & 1.1 & $1.2,[1.3]$ \\
\hline IMP & 88 & 101 & 407 & 0.72 & $0.78,[0.70]$ \\
\hline LFS & 61 & 101 & 377 & 0.98 & $1.3,[1.5]$ \\
\hline OWB & 67 & 101 & 386 & 0.91 & $1.1,[1.0]$ \\
\hline SJP & 71 & 101 & 390 & 0.86 & $1.0,[1.0]$ \\
\hline
\end{tabular}

Table 3. Examples of spectral content, given in terms of period, $T$, for transportation generated seismic signals reported in urban locations.

\begin{tabular}{|c|c|c|c|}
\hline Source & $\begin{array}{l}\text { Spectral } \\
\text { Content (s) }\end{array}$ & Location & Reference \\
\hline \multirow[t]{5}{*}{ Road } & 0.1 to 1.5 & London, UK & This Study \\
\hline & 0.04 to 1 & Bucharest, Romania & Groos and Ritter (2009) \\
\hline & 0.03 to 1 & Auckland, New Zealand & Boese et al. (2015) \\
\hline & $<0.3$ & Long Beach, California, US & Chang et al. (2016) \\
\hline & 0.17 to 0.5 & Wyoming, US & Behm et al. (2014) \\
\hline \multirow[t]{5}{*}{ Rail } & $\begin{array}{l}0.014 \text { to } 0.3, \text { and } \\
20 \text { to } 50\end{array}$ & London, UK & This Study \\
\hline & 0.02 to to 1 & Beijing, China & Chen et al. (2004) \\
\hline & 0.03 to 0.13 & Auckland, New Zealand & Boese et al. (2015) \\
\hline & 0.03 to 0.1 & Long Beach, California & Riahi and Gerstoft (2015) \\
\hline & 20 to 100 & Palisades, US & Sheen et al. (2009) \\
\hline \multirow[t]{3}{*}{ Subway } & $\begin{array}{l}0.01 \text { to } 0.1 \text { (dynamic) } \\
1 \text { to } 100 \text { (quasi-static) } \\
>30 \text { (air-piston) }\end{array}$ & London, UK & This Study \\
\hline & 0.008 to 0.05 & London, UK & Degrande et al. (2006) \\
\hline & $<0.2$, and 20 to 100 & Seoul, South Korea & Sheen et al. (2009) \\
\hline
\end{tabular}



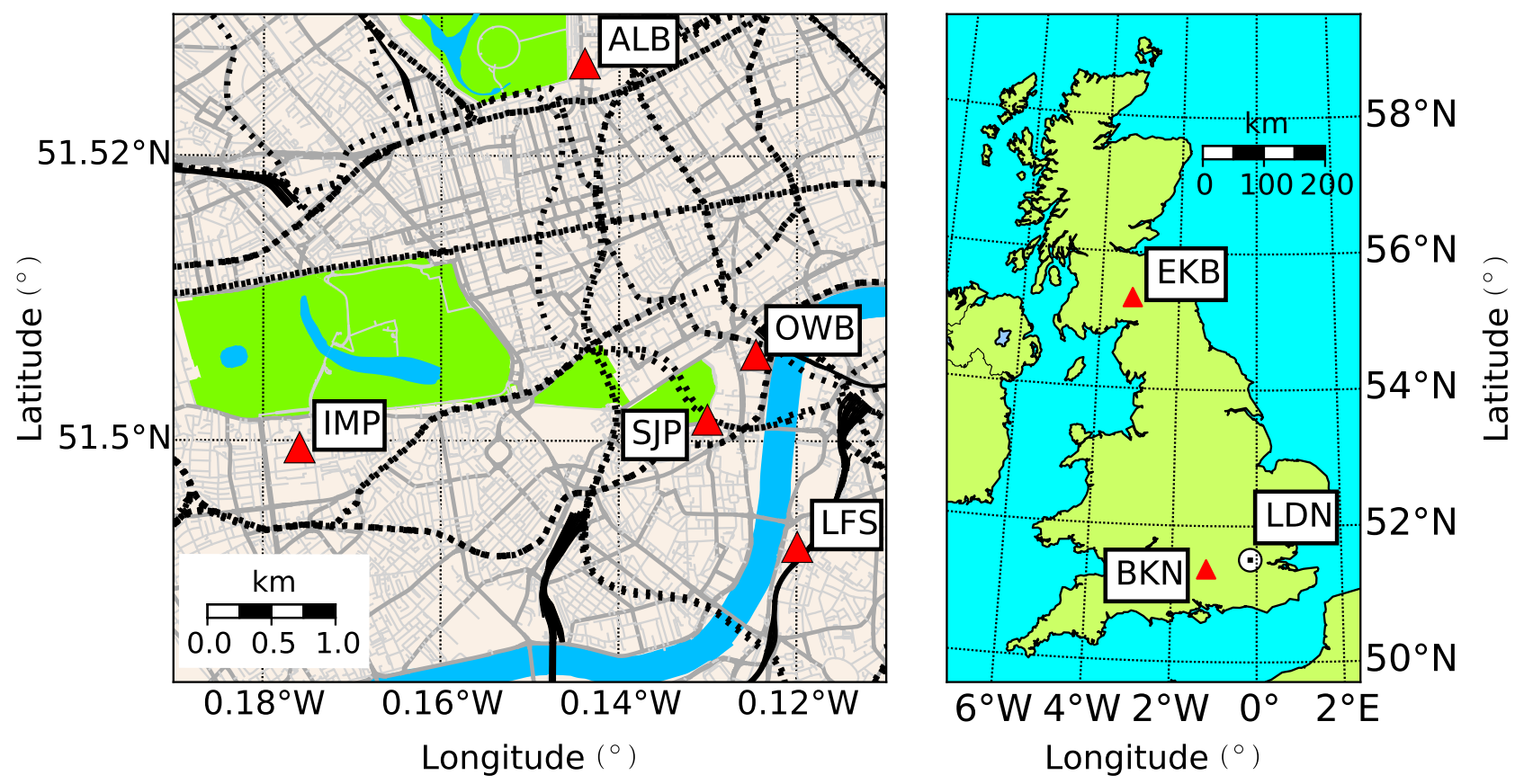

Figure 1. A simplified map (left hand panel) showing stations deployed in central London (red triangles). Roads are shown in grey, with major routes denoted by wider lines. Surface train lines are shown as solid black lines, underground train lines are shown as dashed black lines. The right hand panel shows the location of the two UK stations used to compare against noise levels in London (LDN). Mapping information taken from OpenStreetMap (@ OpenStreetMap contributors). The color version of this figure is only available in the electronic edition. 


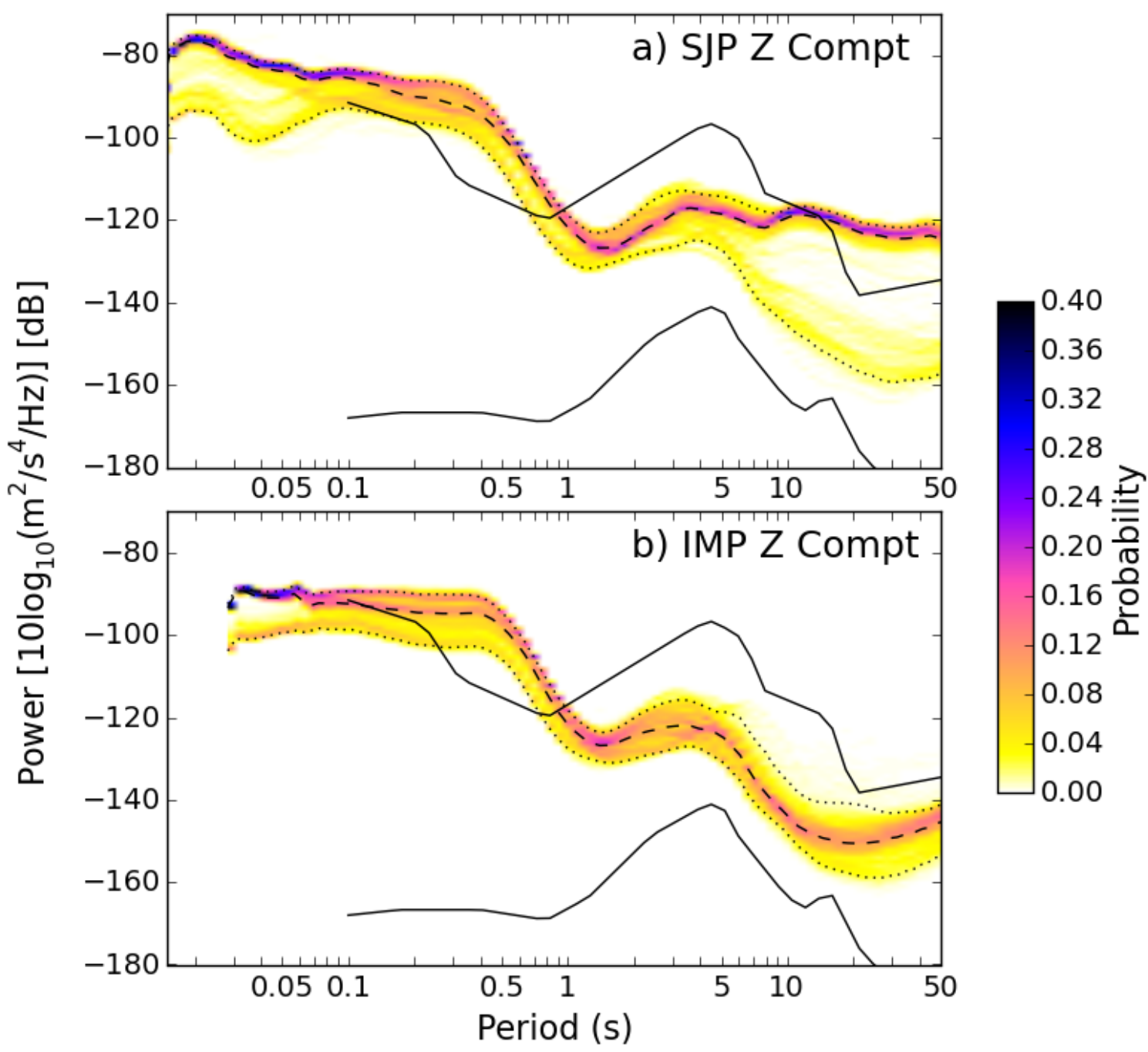

Figure 2. A comparison of the broadband vertical component noise power probability density functions at stations a) SJP and b) IMP, calculated using the methodology of McNamara and Buland (2004). Note the sampling rate differed at the two stations, IMP $=100 \mathrm{~Hz}, \mathrm{SJP}=200 \mathrm{~Hz}$. Solid black lines are the New Low and High Noise Models of Peterson (1993). Dashed black lines are the median PDF values, while dotted black lines are the 5 and $95 \%$ PDF values at each period. The color version of this figure is only available in the electronic edition. 


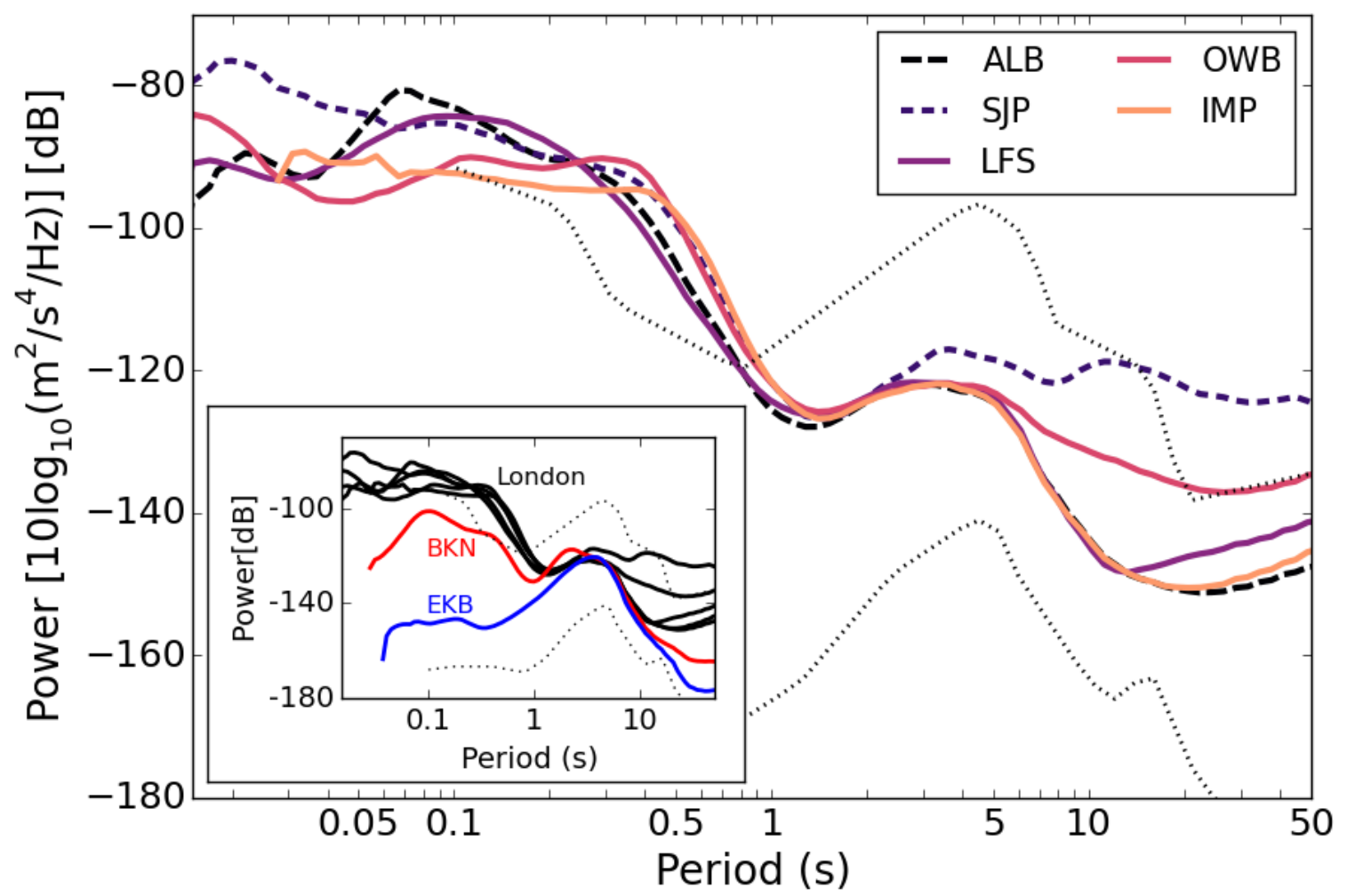

Figure 3. Median vertical component noise power levels calculated at the five broadband sensors within the temporary London station network (data values provided in Table S1, available in the electronic supplement to this article). Sensor names are given in the legend; locations are shown in Figure 1. The black dotted lines are the vertical acceleration New Low and High Noise Models of Peterson (1993). The inset compares the London median noise levels with those from two other UK stations: BKN located at AWE Blacknest (51,364N,1.187W), and EKB located at Eskdalemuir, southern Scotland (55.334N,3.192W). The data for BKN and EKB were taken from the same time period as the OWB deployment (Table 1). The color version of this figure is only available in the electronic edition. 
a)

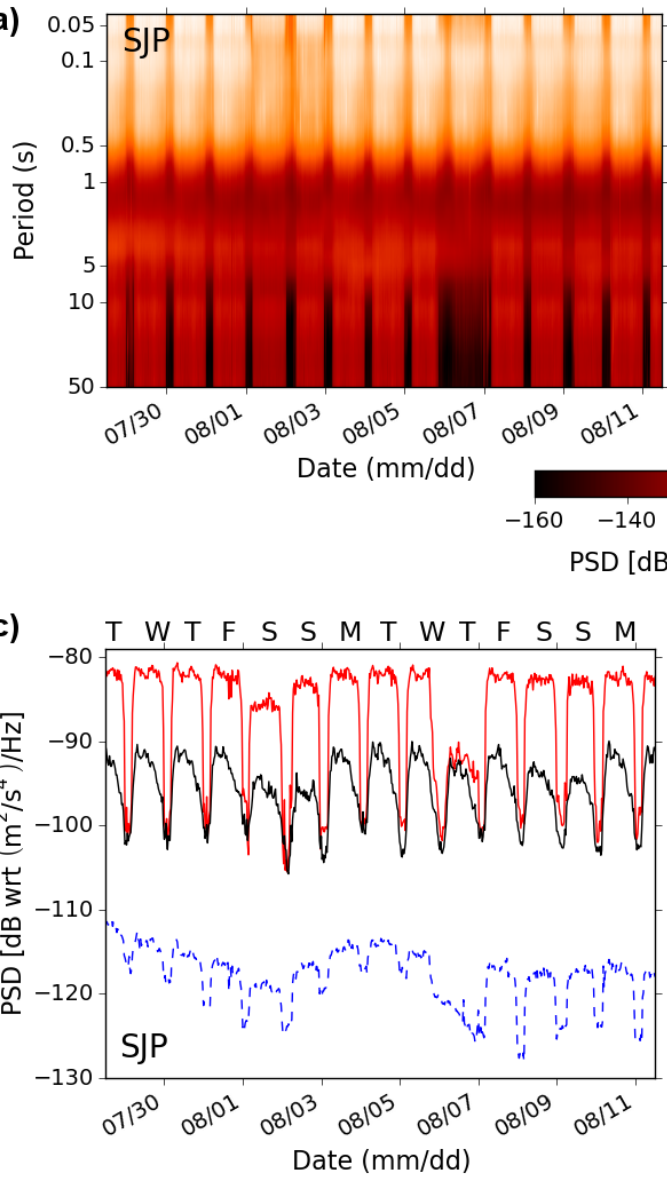

e)

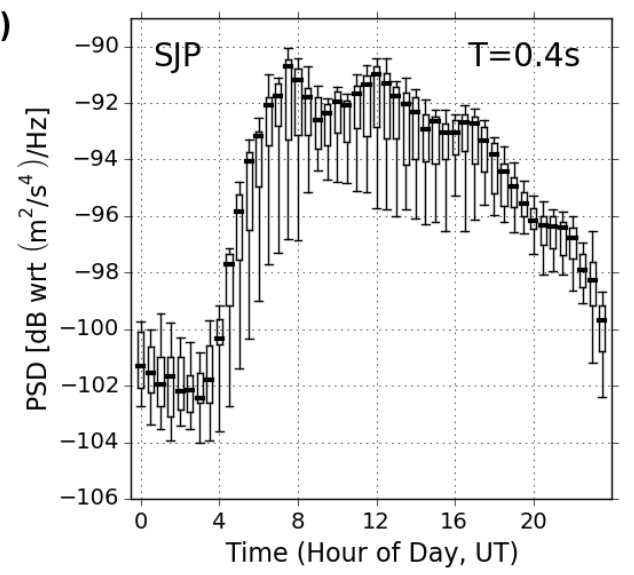

b)

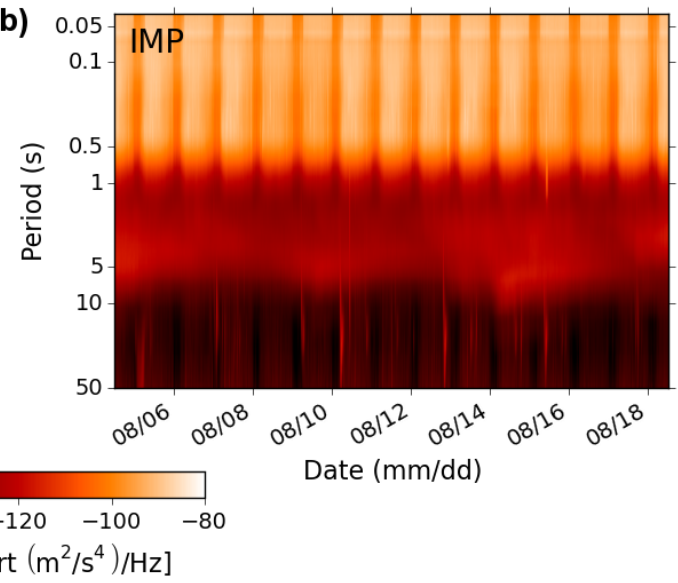

f)

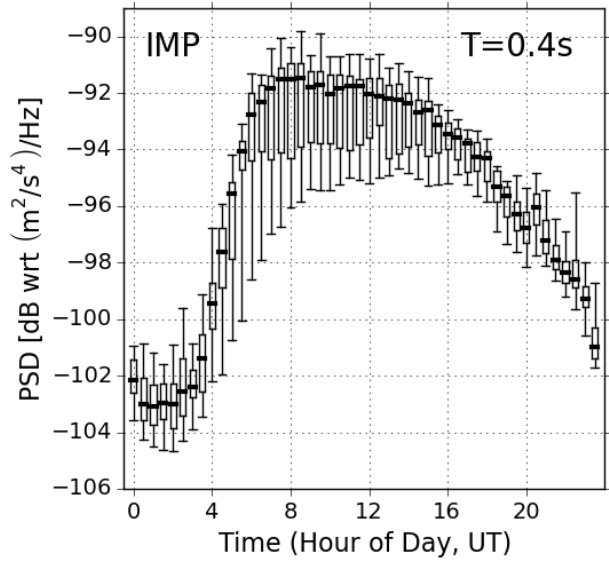

Figure 4. Diurnal variations of vertical component noise measurements at stations SJP (panels a, c and e) and IMP (panels b, $d$ and f). The upper panels show the variation of noise power as a function of time and period. Note that although the $y$-axis scales are identical the time periods are different (but overlapping) due to different deployment schedules. The middle panels show diurnal noise variations at three periods, representing horizontal slices through panels a) and b). The lower plots are boxplot summaries of the noise variation in half-hour bins across the entire station deployments at $0.4 \mathrm{~s}$. The thick central line indicates the median value, the box limits are the 25th and 75th percentiles, while the whiskers represent the 5th and 95th percentiles of the noise distributions. The color version of this figure is only available in the electronic edition. 

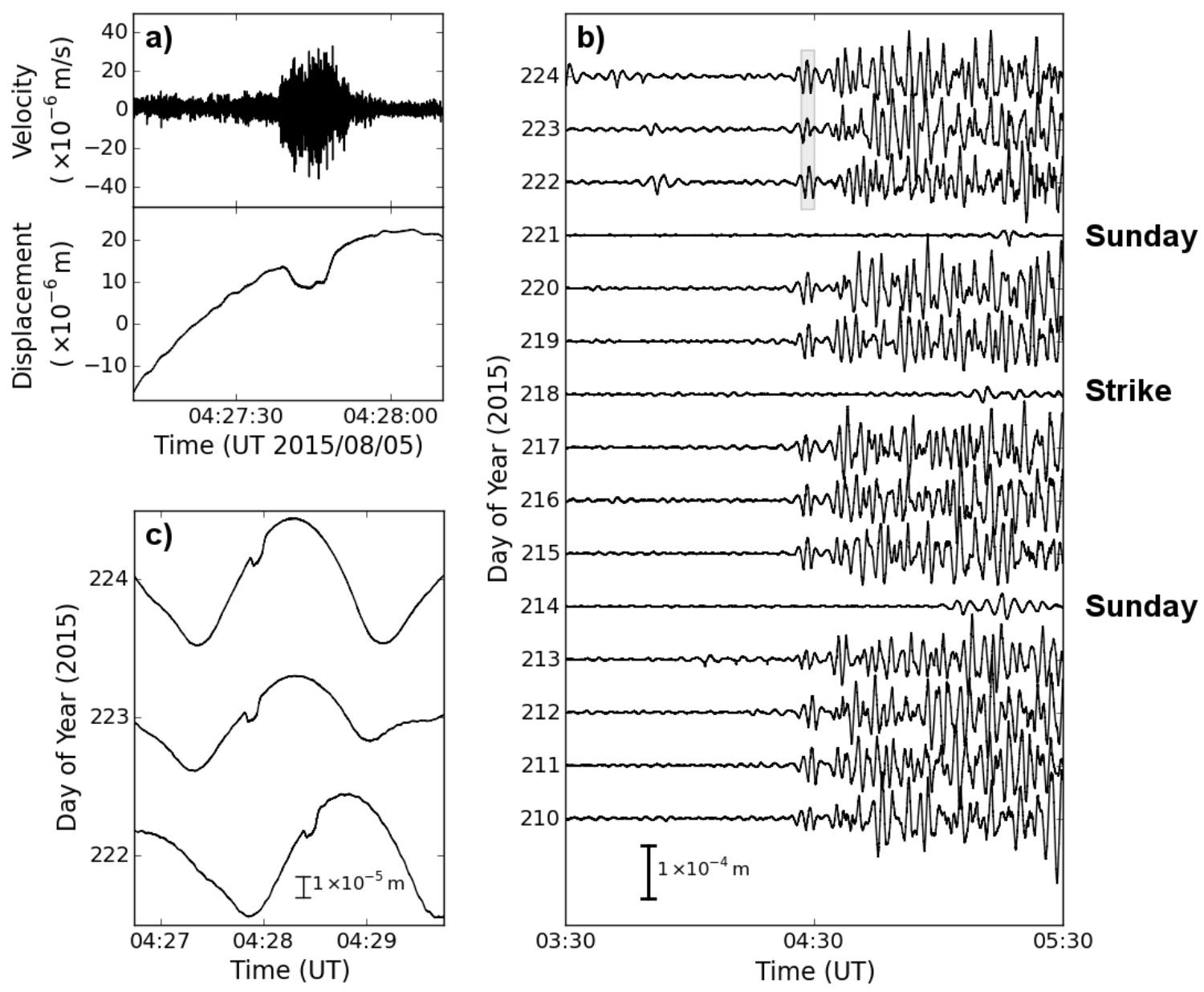

Figure 5. The effect of subway trains on recordings at SJP. Panel a) shows the vertical ground velocity, and displacement, associated with the passage of one Eastbound train beneath station SJP. Panel b) shows the long-period vertical displacement oscillations associated with the start-up of train services in the subway every morning, and c) shows the details of the oscillations from three days (corresponding to the light grey box in panel b). All traces are unfiltered, except for the high-pass filter discussed in the Methods section that suppresses periods $>200$ s to reduce instrument response deconvolution artifacts. 

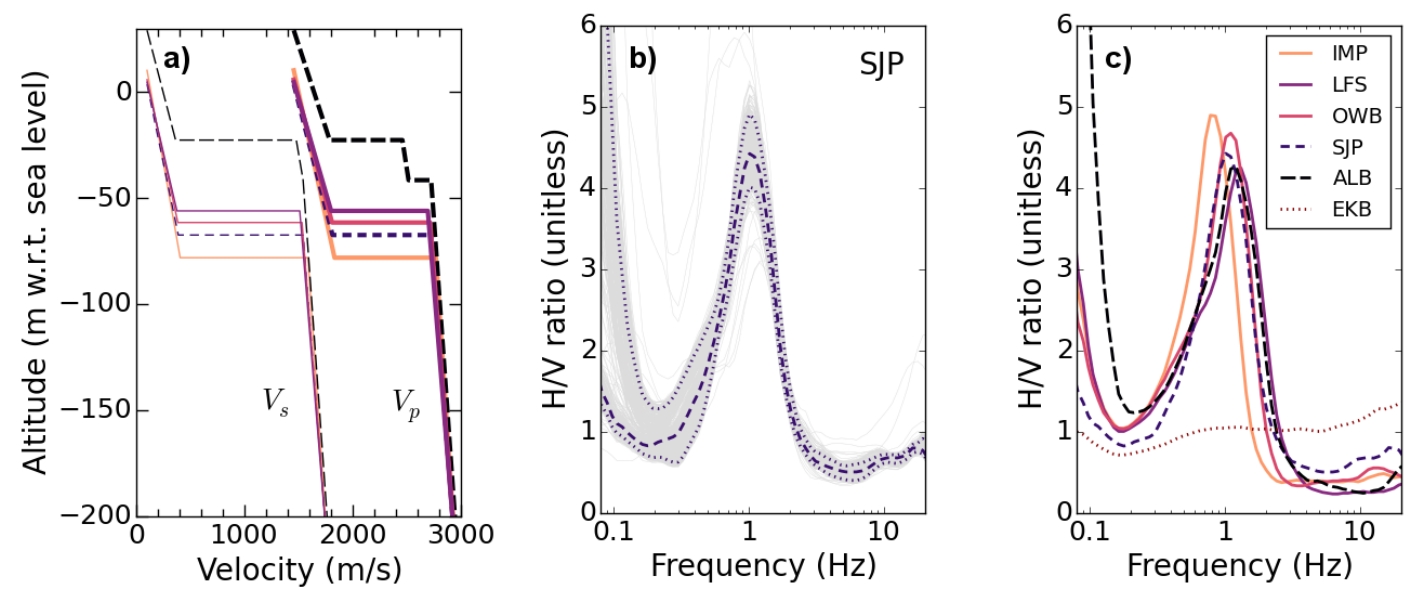

Figure 6. Confirmation of a low-velocity overburden from the seismic data. Panel a) shows velocity profiles for the upper layers of the 4-layer simplified BGS geology-derived velocity model: $P$-wave speeds as thick lines, $S$-wave speeds as thin lines. Panel b) shows H/V ratio spectra calculated from each half-hour seismic spectra recorded at SJP (grey lines). The thick dashed line is the median value at each frequency, the dotted lines provide the 5 and $95 \%$ percentile values. Panel c) shows the median $\mathrm{H} / \mathrm{V}$ ratio spectra for the London deployments and the seismometer at EKB, Eskdalemuir (Figure 1). The color version of this figure is only available in the electronic edition. 